\title{
100 Jahre Deutsche Anwalt- und Notar-Versicherung
}

\author{
Jubiläum am 20. Oktober 2007 in Halle
}

Im Oktober 2007 kann die Deutsche Anwalt- und Notar-Versicherung (DANV), Sonderabteilung der zur ERGO-Gruppe gehörenden HamburgMannheimer VersicherungsAG auf 100 Jahre Geschäftstätigkeit zurückblicken. Über das Berufsstände- und Beiratsabkommen ist die DANV heute mit 14 Kammern beziehungsweise Verbänden ihrer Kundengruppen verbunden - auch mit dem Deutschen Juristinnenbund (djb). Der djb ist im Jahr 1992 dem Berufsstände- und Beiratsabkommen mit der DANV beigetreten. Delegierte des Bundes ist heute Rechtsanwältin Margret Diwell.

Aufgrund einer Entscheidung des Deutschen Anwaltstages 1905 in Hannover wurde 1907 eine "Ruhegehalts-, Witwen- und Waisenkasse für deutsche Rechtsanwälte und Notare" gegründet - als Versicherungsverein auf Gegenseitigkeit. Sitz der Kasse war Halle an der Saale. Der Name der Gesellschaft wurde später in Deutsche Anwalt- und Notarversicherung geändert. Nach dem Zweiten Weltkrieg und dem Verbot der Geschäftstätigkeit in Halle musste die DANV praktisch wieder bei Null anfangen. Als Partner fand sie in der Hamburg-Mannheimer eine Versicherungsgesellschaft, die sicherstellte, dass die Deutsche Anwalt- und Notar-Versicherung in berufsständischer Tradition nach eigenen, bedarfsgerechten Tarifen, mit getrennten Gewinnverbänden und als wirtschaftlich selbständige Verwaltungseinheit weitergeführt werden konnte. Diese Eigenständigkeit unterstreicht auch das „Berufsstände- und Beiratsabkommen" von 1956, das den beteiligten Kammern und Verbänden unter anderem das Recht gibt, ein Mitglied ihres Vertrauens in den Beirat der DANV zu delegieren. Dieser Beirat berät die Geschäftsführung des Standesversicherers.

Heute wendet sich die DANV an alle Angehörigen von rechts-, steuer-, unternehmensberatenden und wirtschaftsprüfenden Berufe, an deren Familienmitglieder sowie an deren Mitarbeiterinnen und Mitarbeiter.

Mit einem beeindruckenden Festakt in der Ulrichskirche und einem rauschenden Fest in der Georg-FriedrichHändel-Halle in der Gründungsstadt Halle hat die Deutsche Anwalt- und Notar-Versicherung ihr 100-jähriges Jubiläum am 20. Oktober 2007 gefeiert. Die Anwaltschaft war bei diesem Ereignis mit vielen früheren und amtierenden Präsidenten vertreten. Den Festvortrag hielt der Präsident des Deutschen Anwaltvereins, Herr Rechtsanwalt Hartmut Kilger, zum Thema „Freier Beruf und Alter- und Invaliditätsvorsorge”.

„Frauen in die Aufsichtsräte!” - ja. Aber als einzige Frau im Beirat einer so alten und renommierten Versicherung habe ich mich auch sehr wohl gefühlt.
Margret Diwell

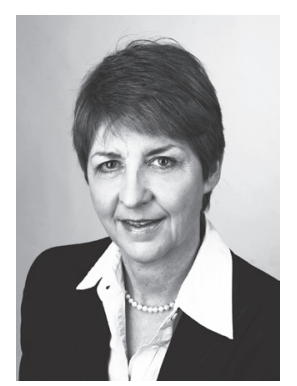

Margret Diwell

Von 2001 bis 2005

Präsidentin des djb.

Seit einigen Jahren

vertritt sie den djb im

Beirat der DANV.

Sie ist Rechtsanwältin, Fachanwältin für

Familienrecht in Berlin und Präsidentin des Berliner Verfassungsgerichtshofs.

FamRZ Jahrgänge 1985 bis 2006 ,

tadelloser Zustand, preiswert abzugeben (Jahrgänge 1985-1996 gebunden, 1997-2006 ungebunden, aber vollständig mit Inhaltsverzeichnis und Einbanddecken). Nachfragen an die Geschäftsstelle Chiffre 08-01 